\title{
Contribution of Potential Evaporation Forecasts to 10-day streamflow forecast skill for the Rhine river - Supplemental Figures
}

Bart van Osnabrugge ${ }^{1,2}$, Remko Uijlenhoet ${ }^{2}$, and Albrecht Weerts ${ }^{1,2}$

${ }^{1}$ Deltares, Operational Water Management Department, Delft, The Netherlands

${ }^{2}$ Wageningen University, Hydrology and Quantitative Water Management Group, Wageningen, The Netherlands

Correspondence: Bart van Osnabrugge (Bart.vanOsnabrugge@ deltares.nl) 
Seasonal mean difference in actual evaporation

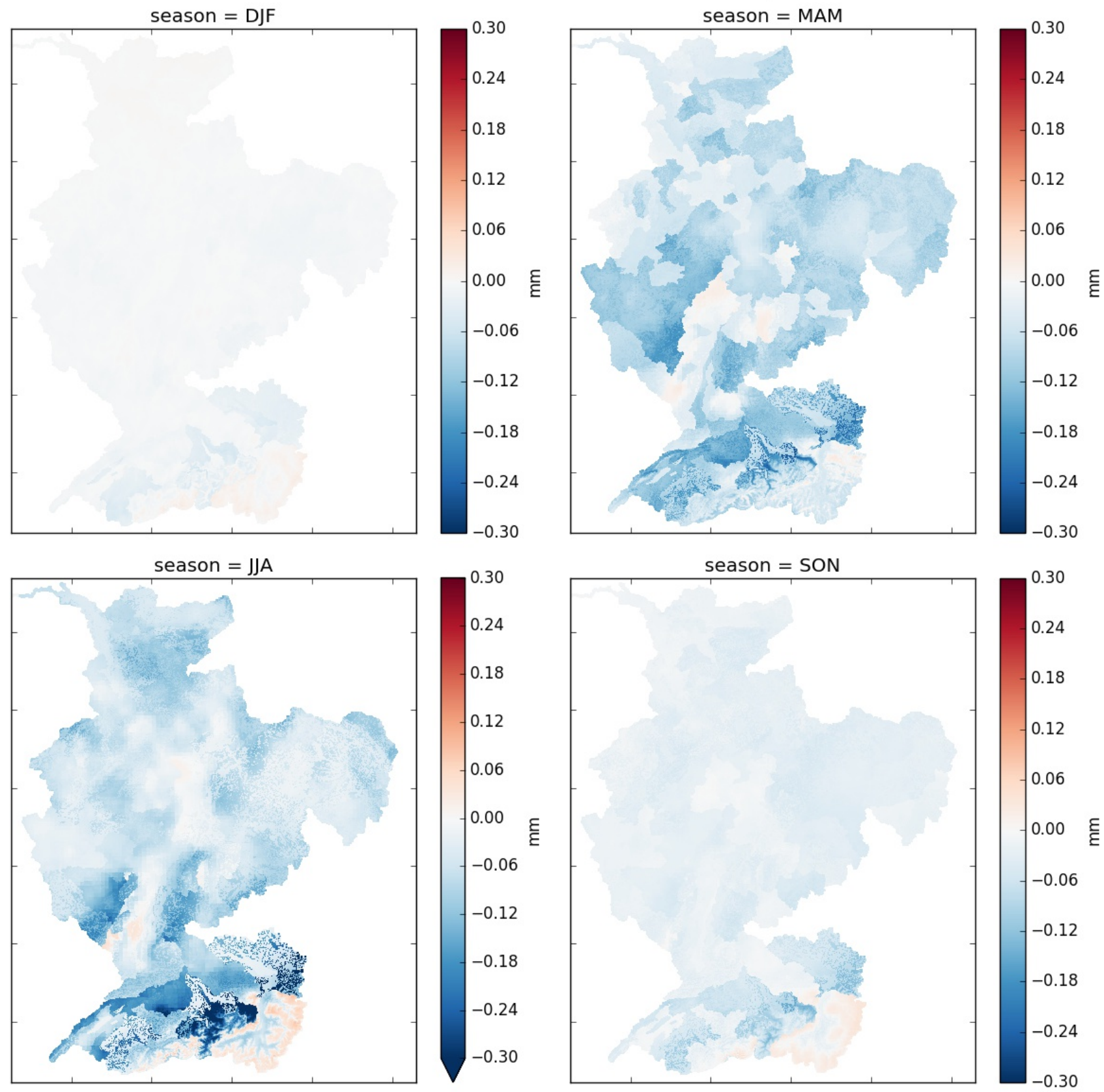

Figure 1. Seasonal Mean Difference in calculated actual evaporation (aevap) for each season. Actual evaporation includes evaporation from interception. 
Seasonal mean difference in interception storage

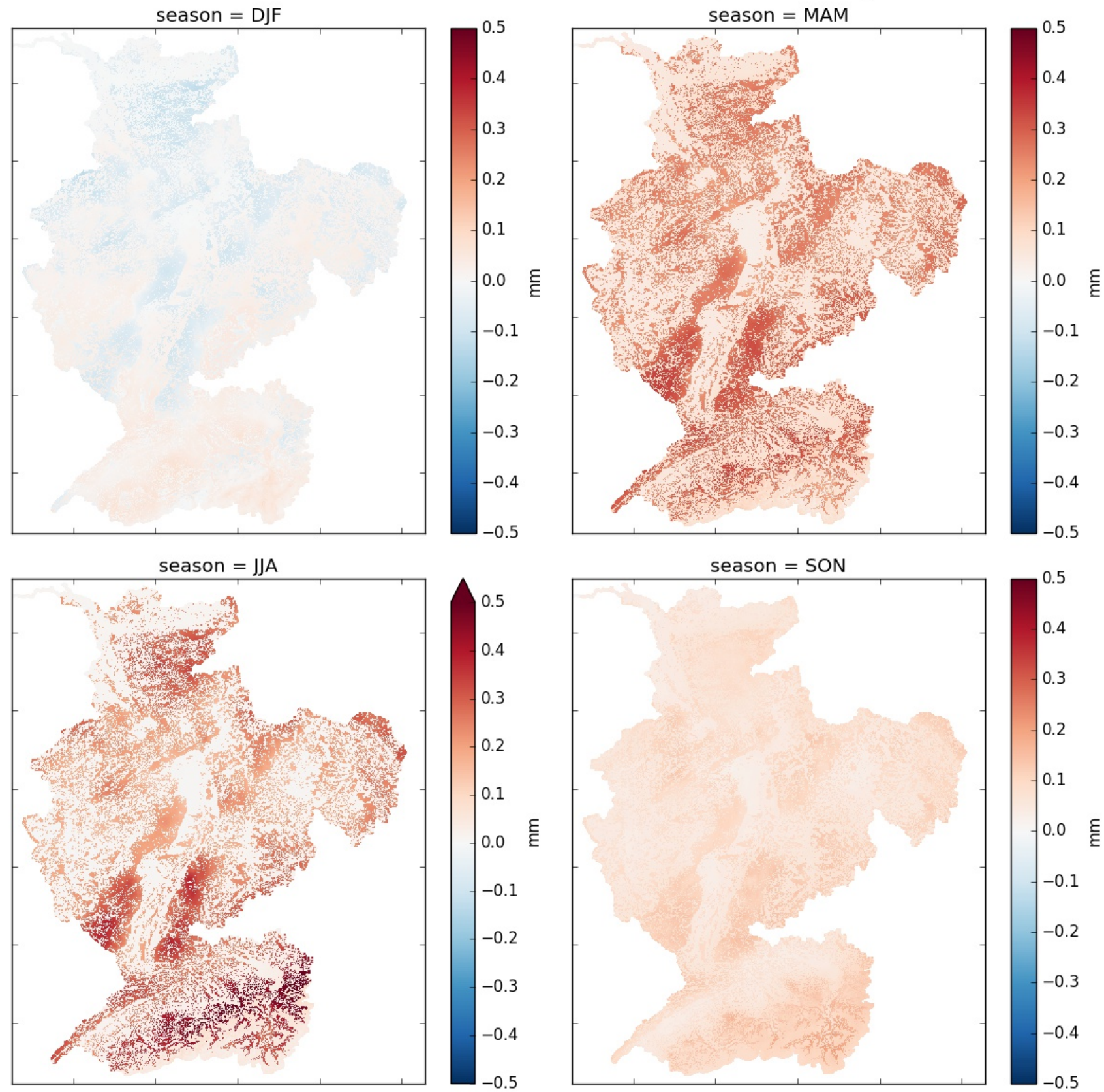

Figure 2. Seasonal Mean Difference in calculated interception storage (ic) for each season. This is not the average interception flux, but the average storage in the interception reservoir so that wetter interception stores means less interception. 


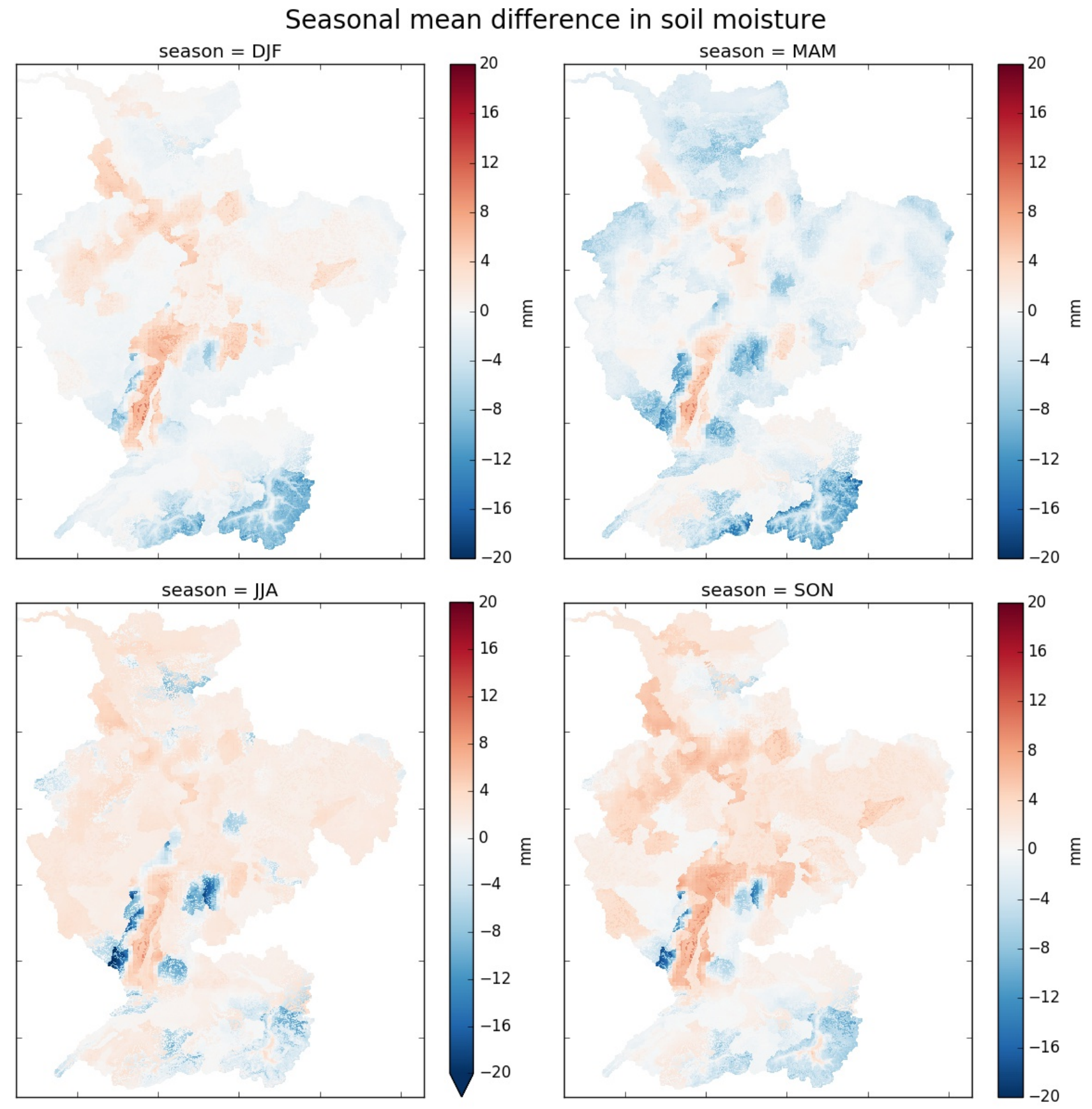

Figure 3. Seasonal Mean Difference in calculated soil moisture (sm) for each season. 
Seasonal mean difference in upper zone storage

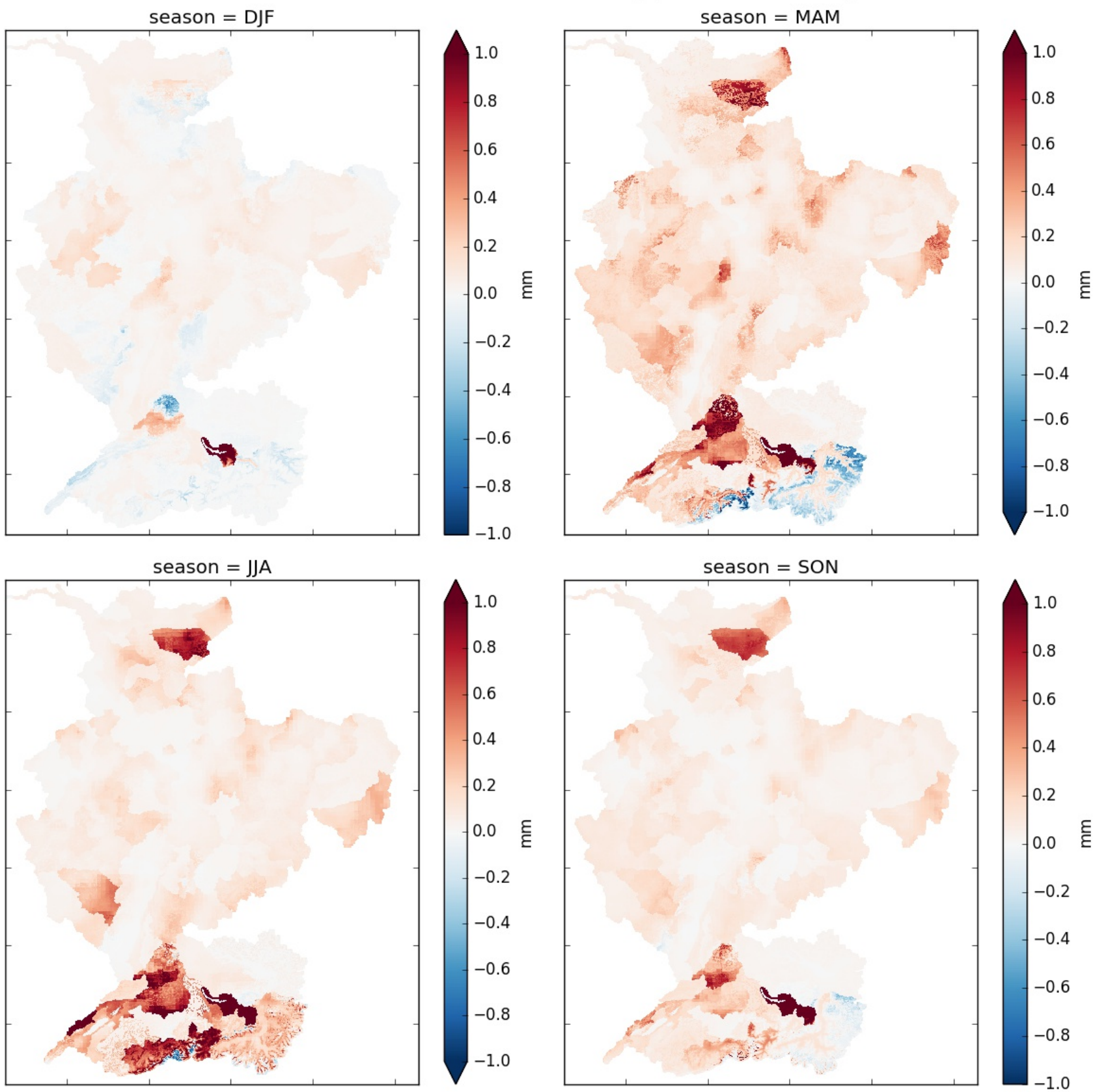

Figure 4. Seasonal Mean Difference in calculated upper zone storage (uz) for each season. 
Seasonal mean difference in lower zone storage
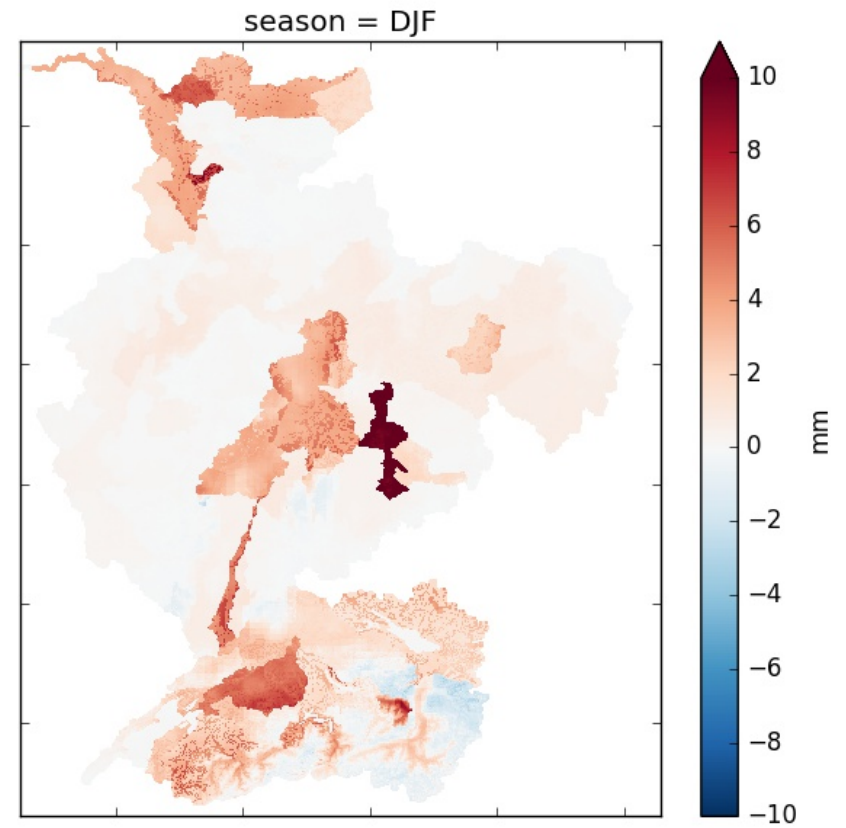

season $=$ MAM
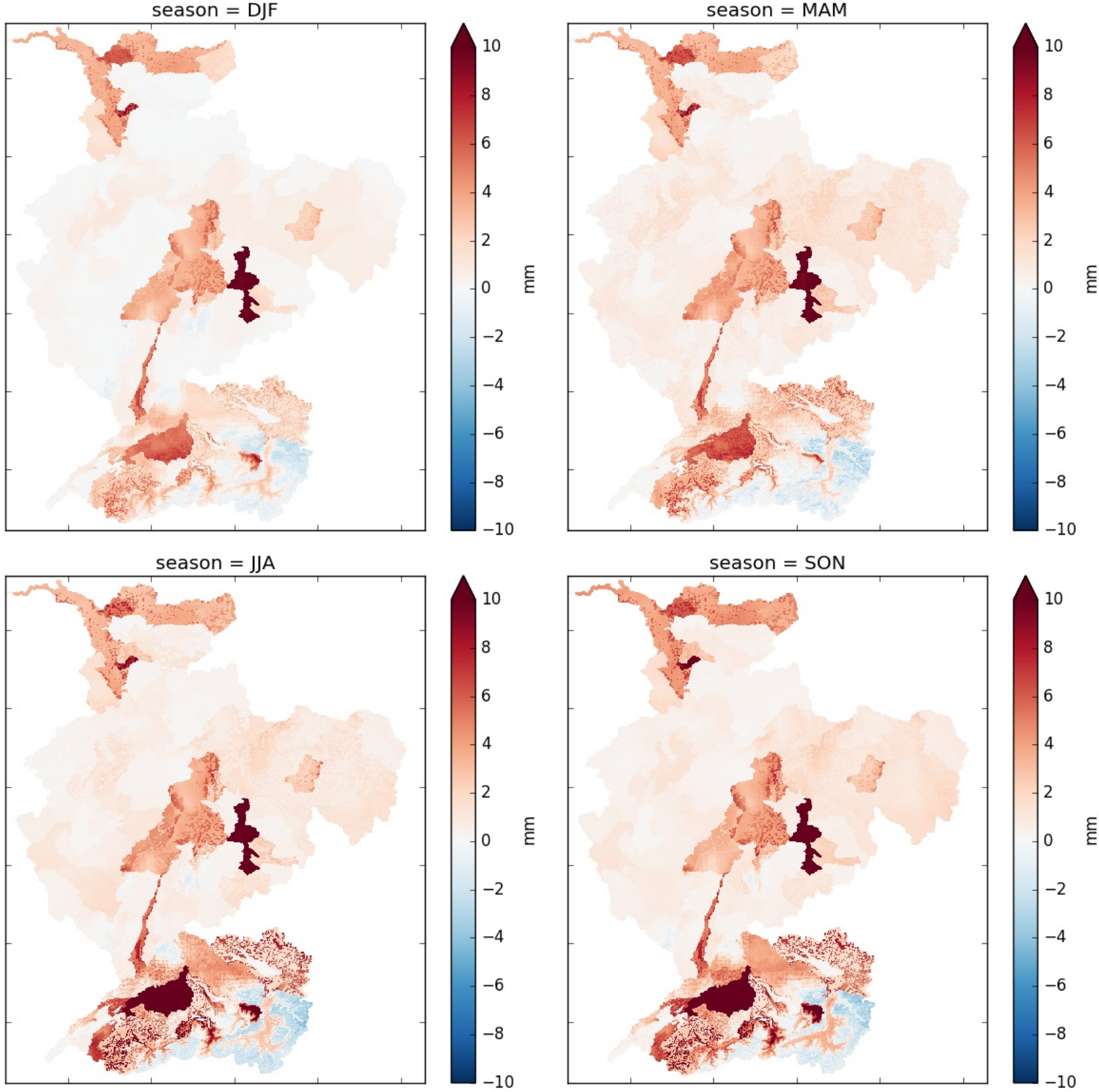

Figure 5. Seasonal Mean Difference in calculated lower zone storage (lz) for each season. 


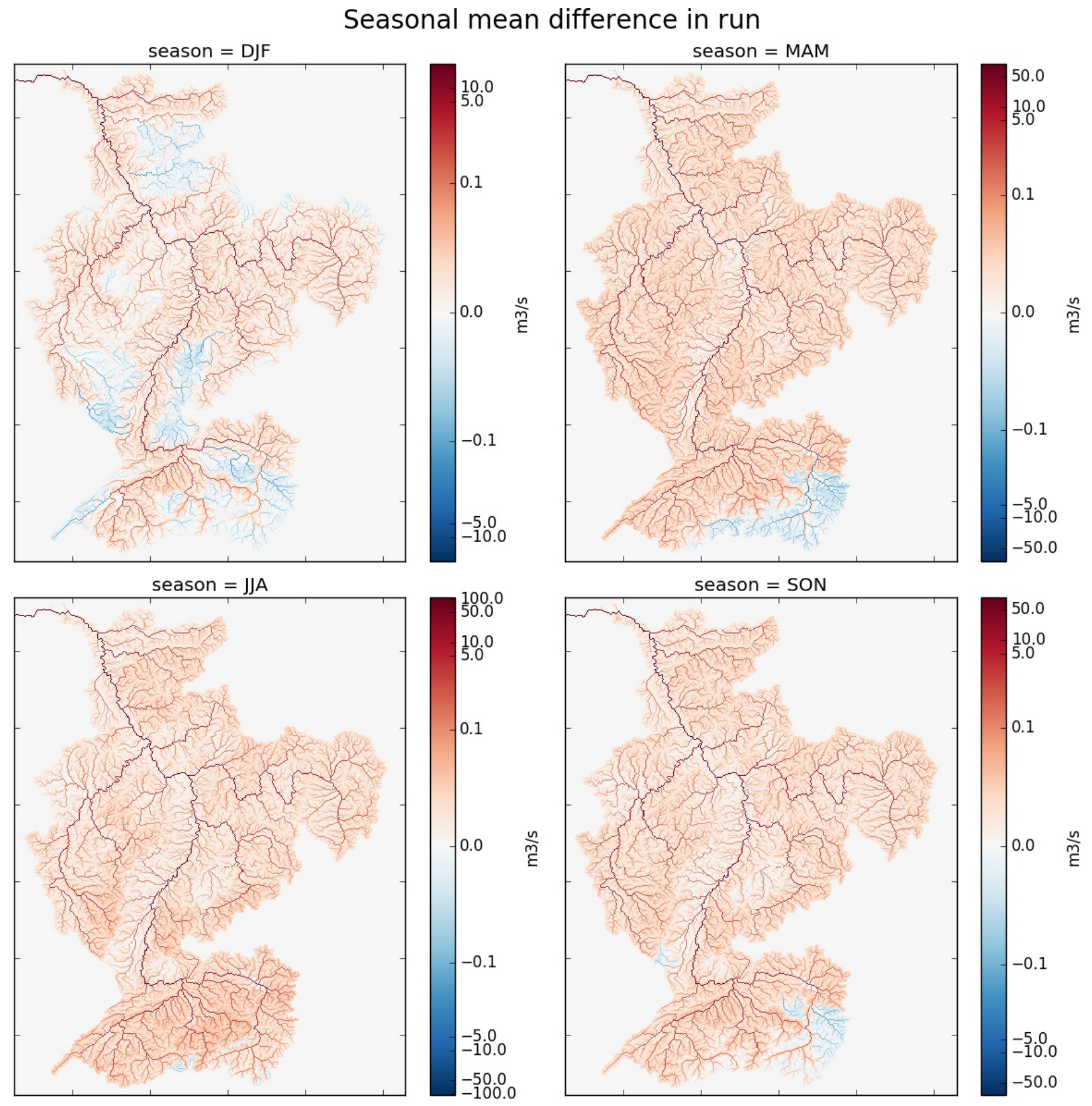

Figure 6. Seasonal Mean Difference in calculated discharge (run) for each season. 